\title{
TRATAMIENTO ENDOSCÓPICO DEL REFLUJO VÉSICOURETERAL EN PACIENTES PEDIÁTRICOS DIAGNOSTICADOS DE VEJIGA NEURÓGENA. RESULTADOS $Y$ EVOLUCIÓN A LARGO PLAZO
}

\author{
Francisco Estornell Moragues, Agustín Serrano Durbá, Carlos Domínguez Hinarejos, Lidia Ayuso \\ González, Mario Martínez Verduch y Fernando García Ibarra.
}

Servicio de Urología Pediátrica. Hospital Universitario La Fe. Valencia. España.

\begin{abstract}
Resumen.- OBJETIVO: Conocer los resultados, complicaciones y la evolución de ocho pacientes diagnosticados de Vejiga neurógena (VN), intervenidos de Reflujo vesicoureteral (RVU) mediante la inyección subureteral de sustancias inertes, intentando precisar su indicación en el esquema terapéutico de la alteración vesical neurógena.
\end{abstract}

MÉTODOS: Revisión retrospectiva de los resultados obtenidos y de las complicaciones evidenciadas durante los controles evolutivos efectuados a ocho pacientes en edad pediátrica con VN secundaria a diferentes patologías, diagnosticados de RVU, tratado mediante inyección subureteral de pasta de teflón (1 caso), polidimetilsiloxano (6) y copolímero de dextranómero y ácido hialurónico (1).
RESULTADOS: De los 11 uréteres tratados en 8 (72.7\%) el RVU curó después de la primera inyección. De los 3 uréteres con persistencia del RVU, en dos cesó después del segundo tratamiento endoscópico (TE). La eficacia del TE después de la segunda inyección alcanzó el 90.9\%. En dos casos unilaterales evidenciamos RVU contralateral que curó mediante TE en uno siguiendo pauta conservadora el segundo. Durante el periodo de seguimiento (tiempo medio: $51.8+/-28.5$ meses) presentaron complicaciones 4 casos. Reapareció el RVU en dos, observamos RVU contralateral en uno a los 19 meses del primer tratamiento y en otro evidenciamos ureterohidronefrosis bilateral con infecciones urinarias recurrentes que precisó de cistoplastia de aumento.

CONCLUSIONES: El TE es una opción eficaz cuando se decide el tratamiento quirúrgico del RVU en un paciente con vejiga neurógena. Es necesario seguir la evolución a largo plazo de los pacientes intervenidos, sobre todo aquellos con capacidad y acomodación vesical alterada y uretra activa o disinérgica, ante la posibilidad de aparición del RVU ya curado.

Palabras clave: Reflujo vésico-ureteral. Tratamiento endoscópico. Vejiga neurógena.

Summary.- OBJECTIVES: To know the results, complications and outcomes of eight patients with the diagnosis of neurogenic bladder (NB) who underwent vesicoureteral reflux surgery by subureteral injection of inert substances, trying to precise its indication in the therapeutic scheme for neurogenic bladder dysfunction.

METHODS: Retrospective review of the results and complications recorded during follow-up in eight pediatric patients with NB secondary to various pathologies and the diagnosis of VUR treated by subureteral injection of Teflon paste (1 case), 
polydimethylsiloxane (6) and dextranomer/hyaluronic acid copolymer (1).

RESULTS: In 8 (72.7\%) of the 11 ureters treated VUR was CUred after first injection. VUR stopped after second endoscopic treatment in 2 of the 3 ureters with persistent VUR. The efficacy of endoscopic treatment after second injection achieved 90.9\%. In 2 unilateral cases we observed contralateral VUR, which cured in one case after endoscopic treatment and the other one followed a conservative scheme. Over the follow-up period (Mean FU time 51.8+/-28.5 months) 4 cases presented complications. VUR recurred in two: in one contralateral VUR was detected 19 months after first treatment, the other one presented bilateral ureterohydronephrosis with recurrent urinary tract infections and required augmentation cystoplasty.

CONCLUSIONS: Endoscopic treatment is an effective option when choosing surgical treatment for VUR in a patient with neurogenic bladder. It is necessary to follow the long-term outcome of patients after surgery, mainly those with abnormal bladder capacity and compliance and active or dyssynergic urethra due to the possibility of recurrence of the VUR.

Keywords: Vesicoureteral reflux. Endoscopic treatment. Neurogenic bladder.

\section{INTRODUCCIÓN}

El Reflujo Vesico Ureteral (RVU) es una de las complicaciones que pueden aparecer en la evolución de los pacientes diagnosticados de Vejiga Neurógena (VN), durante la edad pediátrica. La indicación del tratamiento quirúrgico para lograr su resolución y evitar los efectos nocivos sobre el riñón, depende de la evaluación de diferentes factores como: grado de RVU, presencia de bacteriuria sintomáti$\mathrm{ca}$, aparición de cicatrices renales, afectación funcional del parénquima y de las características urodinámicas de la vejiga. El tratamiento endoscópico (TE), mediante la inyección subureteral de sustancias inertes es, en la actualidad, la técnica de elección en el manejo quirúrgico del RVU primario. Su aplicación en la terapéutica de los secundarios a una disfunción vésico-uretral de etiología neurógena, se ha incrementado en los últimos años, aunque su eficacia a largo plazo debe valorarse con el paso del tiempo y la aportación de la experiencia de los diversos equipos de trabajo.

El objetivo de nuestro artículo es revisar de manera retrospectiva los resultados alcanzados, las complicaciones evidenciadas y la evolución constatada en ocho pacientes diagnosticados de $\mathrm{VN}$ secundaria a diferentes patologías, intervenidos de RVU mediante la inyección subureteral de diferentes biomateriales, intentando precisar su indicación en el esquema terapéutico de la alteración vesical neurógena.

\section{MATERIAL Y MÉTODO}

Desde octubre de 1997 a enero de 2006, 8 pacientes, 2 varones y 6 mujeres, diagnosticados de $\mathrm{VN}$ secundaria a mielomeningocele lumbosacro (5), meningocele sacro (1), tumor medular epidermoide y neuroblastoma resecados anteriormente (2), que presentaban $\mathrm{RVU}$, han sido intervenidos mediante TE. Excluimos a un paciente operado previamente de RVU mediante ureterocistoneostomía antirreflujo bilateral según técnica de Cohen, que presentaba recidiva bilateral y a otro con estenosis uretral concomitante.

En todos los casos practicamos exploración urodinámica en el periodo preoperatorio. Las variables: capacidad funcional, acomodación, presencia de hiperactividad durante el llenado y presión detrusoriana de escape fueron evaluadas.

La capacidad vesical fue valorada con respecto a la edad según la fórmula de capacidad vesical en cc. = a $24.5 \times$ edad + 62. (1). Definimos la acomodación como alterada cuando su valor era inferior a $10 \mathrm{ml} / \mathrm{cm}$. $\mathrm{H}_{2} \mathrm{O}$. Cuatro pacientes seguían la pauta de: cateterismo intermitente (Cl) y anticolinérgicos administrados por vía oral, 2 con $\mathrm{Cl}$ y 2 no llevaban tratamiento pues no aceptaron nuestras recomendaciones terapéuticas. Todos los niños recibían profilaxis antibiótica nocturna.

La intensidad del RVU fue evaluada según la clasificación del Comité Internacional para el estudio del reflujo (2). Si la valoración había sido realizada mediante cistogammagrafía isotópica consideramos los RVU leves como grado I y II, los moderados como III y los severos como IV y $\mathrm{V}$.

La intervención se practicó según la técnica de inyección clásica descrita por O’Donnell y Puri (3). En los casos unilaterales sólo se trató el lado afecto, previa inspección del meato contralateral y su consideración endoscópica como normal. La decisión de intervenir los uréteres de grado I se tomó en base al grado de RVU contralateral. Todos los pacientes recibieron profilaxis antibiótica peroperatoria.

El control postoperatorio se efectuó mediante ecografía al mes y Cistouretrografía Miccional Seriada (CUMS) o isotópica a los tres meses del acto quirúrgico. El resultado fue considerado bueno cuando se demostraba la ausencia de RVU, en este caso la evolución era seguida según nuestro protocolo de $\mathrm{VN}$ consistente en control clínico y bacteriológico de orina cada tres meses, ecografía cada seis y CUMS cuando observamos ectasia en la vía urinaria o aumento de la dilatación si la hubiere previamente, o ante la presencia de bacteriuria sintomática. La función renal fue evaluada mediante gammagrafía renal y las determinaciones analíticas practicadas por la Sección de Nefrología. Si persistía el RVU, el paciente era propuesto para nuevo tratamiento endoscópico o se valoraba la utilidad de practicar una cistoplastia de ampliación.

La presencia de RVU contralateral en los casos unilaterales intervenidos no es considerado como mal resultado, sino como una complicación del acto quirúrgico. 
El periodo de seguimiento osciló entre los 13 y 94 meses (media: $51.8+/-28.5$ meses). Durante este tiempo todos los niños siguieron el tratamiento de su alteración vesical neurógena y los controles clínicos preceptivos. En nuestra Unidad los pacientes son controlados hasta los 15 años de edad, siendo derivados posteriormente al Servicio de Urología de su Hospital de referencia.

\section{RESULTADOS}

De los ocho pacientes, 5 presentaban RVU unilateral y 3 bilateral, siendo el número de unidades renoureterales afectas de 11 . El grado de RVU por uréter fue de I en 1 caso, II en 5; III en 3 y IV en 2 . Si consideramos la intensidad máxima por paciente, en tres niños observamos grado II, en tres casos grado III y en dos grado IV.

Indicamos el TE por presentar: episodio de pielonefritis aguda en 5 casos, aumento de la ectasia de la vía urinaria y bacteriuria sintomática en 2 pacientes y por aumento de la dilatación ureteral con paso del RVU de uni a bilateral y evidencia de empeoramiento de las variables urodinámicas en un niño.

En la Tabla I exponemos el tratamiento practicado en cada paciente, su edad, resultado obtenido, las características urodinámicas y el grado de RVU. De su análisis podemos observar que la exploración urodinámica previa al
TE permitió clasificar la alteración funcional como: detrusor arrefléxico con uretra activa en tres pacientes; detrusor arrefléxixo con uretra activa y capacidad funcional disminuida en dos casos; detrusor arrefléxico con uretra activa y acomodación deficiente en dos niños y detrusor hiperrefléxico con uretra disinérgica y acomodación deficiente en un paciente.

La edad del paciente cuando se efectuó la primera inyección subureteral osciló entre los 3 y los 13 años y 9 meses (edad media: 8.4 +/- 4.5 años).

El material empleado fue: polidimetilsiloxano (Macroplastique ${ }^{\circledR}$ ) en nueve uréteres, politetrafluoroetileno suspendido en glicerina y polisorbato (Teflon $囚$ ) en uno y copolímero de dextranómero y ácido hialurónico (Deflux®) en otro. El volumen inyectado en cada meato ureteral varió entre los 0.650 cc. y los 1.5 cc. (volumen medio: 0.9 +/- 0.2 cc.).

El resultado obtenido después del primer tratamiento fue bueno en 8 de 11 uréteres (72.7\%). En los tres restantes evidenciamos persistencia del RVU. Si consideramos el resultado por pacientes, en 4 de 8 (50\%) fue bueno y en los otros cuatro constatamos su persistencia en dos, son los uréteres ya comentados, y la aparición de RVU contralateral en otros dos.

De los cinco casos unilaterales, en tres (60\%) el resultado fue bueno y en dos observamos RVU contralateral en la cistografía postoperatoria.

TABLA I. PRIMER TRATAMIENTO ENDOSCÓPICO EFECTUADO. RESULTADO Y COMPLICACIONES.

\begin{tabular}{|c|c|c|c|c|c|c|}
\hline Paciente & RVU & $\begin{array}{l}\text { Edad } \\
\text { (años) }\end{array}$ & Material & Resultado & Complicaciones & Urodinámica \\
\hline 1 & $\|$ & 13 & Teflón® & Bueno & & $\begin{array}{c}\text { Detrusor arrefléxico. } \\
\text { Uretra activa }\end{array}$ \\
\hline 2 & II, II & 12 & 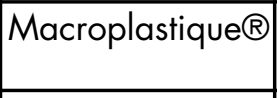 & Bueno & & $\begin{array}{c}\text { Detrusor arrefléxico. } \\
\text { Uretra activa }\end{array}$ \\
\hline 3 & III & 3 & Deflux® & Bueno & & $\begin{array}{c}\text { Detrusor arrefléxico. } \\
\text { Uretra activa. } \\
\text { Acomodación deficiente. }\end{array}$ \\
\hline 4 & IV & 10 & 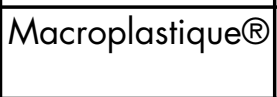 & Bueno & RVU contralateral & $\begin{array}{c}\text { Detrusor arrefléxico. } \\
\text { Uretra activa }\end{array}$ \\
\hline 5 & III, II & 9 & Macroplastique $\mathbb{R}$ & Malo unilateral & $\begin{array}{c}\text { Persistencia RVU } \\
\text { derecho }\end{array}$ & $\begin{array}{c}\text { Detrusor arrefléxico. } \\
\text { Uretra activa. } \\
\text { Acomodación deficiente. }\end{array}$ \\
\hline 6 & III & 8 & Macroplastique $\mathbb{R}$ & Bueno & & $\begin{array}{l}\text { Detrusor hiperrefléxico. } \\
\text { Uretra disinérgica. } \\
\text { Acomodación deficiente. }\end{array}$ \\
\hline 7 & $\mathrm{I}, \mathrm{IV}$ & 4 & Macroplastique $\mathbb{R}$ & Malo bilateral & $\begin{array}{c}\text { Persistencia RVU } \\
\text { bilateral }\end{array}$ & $\begin{array}{c}\text { Detrusor arrefléxico. } \\
\text { Uretra activa. } \\
\text { Capacidad disminuida. }\end{array}$ \\
\hline 8 & II & 3 & Macroplastique $\AA$ & Bueno & RVU contralateral & $\begin{array}{c}\text { Detrusor arrefléxico. } \\
\text { Uretra activa. } \\
\text { Capacidad disminuida. }\end{array}$ \\
\hline
\end{tabular}


No advertimos complicaciones en el postoperatorio inmediato ni en la ecografía de control practicada al mes del acto quirúrgico. En dos pacientes la ectasia ureteral era idéntica a la observada en el periodo preoperatorio.

En la Tabla II mostramos las complicaciones constatadas después del primer TE y durante el periodo de control. Analizaremos cada una de ellas y su tratamiento.

\section{Persistencia del RVU}

En los tres uréteres refluyentes, procedimos a una segunda inyección con el mismo material que en el primer acto quirúrgico, consiguiendo la desaparición del RVU en dos y persistiendo en grado leve en uno. Así pues la eficacia después del segundo TE alcanzó el $90.9 \%$. En la revisión cistoscópica, no visualizamos el habón del material inyectado en la primera ocasión en dos uréteres y en el otro se había desplazado.

\section{Reflujo contralateral}

De los dos casos, en uno se procedió a nuevo tratamiento desapareciendo el paso de orina de vejiga al uréter y en el otro se dejó evolucionar por ser de bajo grado.

\section{Evolución a largo plazo}

De los 8 pacientes, cuatro no han presentado problemas durante el periodo de seguimiento. Sin embargo en los cuatro restantes hemos observado las siguientes complicaciones: reaparición del RVU bilateral (caso 7) y unilateral (caso 5), a los cuatro años y cinco meses y un año y medio respectivamente desde el último acto quirúrgico, siendo de alto grado en la cistografía practicada por presentar episodio de pielonefritis aguda y objetivando en la gammagrafía renal una disminución de función renal porcentual. Ambos pacientes fueron tratados mediante cistoplastia de ampliación. Dilatación bilateral de la vía urinaria con episodios repetidos de infección urinaria sintomática con ausencia de RVU y evidencia de lesiones en la gammagrafía renal en un niño, indicando una cistoplastia de ampliación (caso 8). Aparición de RVU contralateral al año y siete meses de recibir el TE, (caso 6), siendo intervenido mediante inyección subureteral, con buen resultado. En el caso $n^{\circ} 4$ persiste el RVU contralateral cursando sin complicaciones.

\section{DISCUSIÓN}

El RVU es una de las complicaciones que podemos observar durante el periodo de seguimiento de los pacientes con vejiga neurógena. Su etiología responde a la presencia de una hiperpresión vesical generada por las alteraciones funcionales vésico-uretrales. Aquellas vejigas que presentan en el estudio urodinámico: disinergia vésicoesfinteriana, acomodación y capacidad disminuidas con presión detrusoriana de escape alta son candidatas a la presencia de RVU (4-6). La hiperpresión endovesical desestabiliza la unión urétero-vesical logrando su incompetencia y permitiendo el paso de orina en dirección ascendente,

TABLA II. TRATAMIENTO DE LAS COMPLICACIONES. EVOLUCIÓN A LARGO PLAZO.

\begin{tabular}{|c|c|c|c|c|c|c|}
\hline Paciente & $\begin{array}{l}\text { Tiempo de } \\
\text { evolución }\end{array}$ & $\begin{array}{c}\text { Complicación } \\
\text { del primer } \\
\text { tratamiento }\end{array}$ & Tratamiento & Resultado & $\begin{array}{l}\text { Complicación a } \\
\text { largo plazo. } \\
\text { m = meses }\end{array}$ & Tratamiento \\
\hline 1 & $1 a+6 m$ & \begin{tabular}{|c|}
$\mathrm{No}$ \\
\end{tabular} & & & & \\
\hline 2 & $3 a+6 m$ & No & & & & \\
\hline 3 & $1 a+5 m$ & No & & & & \\
\hline 4 & $5 a$ & \begin{tabular}{c|}
$\mathrm{RVU}$ \\
contralateral
\end{tabular} & Conservador & Persiste & & \\
\hline 5 & $7 a$ & $\begin{array}{l}\text { Persistencia } \\
\text { RVU derecho }\end{array}$ & $\begin{array}{c}2^{\underline{a}} \text { inyección } \\
\text { Macroplastique }\end{array}$ & $\begin{array}{l}\text { Persiste RVU } \\
\text { derecho leve }\end{array}$ & $\begin{array}{l}\text { Reaparece RVU } \\
\text { izquierdo } \\
18 \text { m post- } 2^{a} \\
\text { intervención) } \\
\end{array}$ & Cistoplastia \\
\hline 6 & $6 a+2 m$ & & & & $\begin{array}{l}\text { RVU contralate- } \\
\text { ral } 19 \mathrm{~m} \text { post } 1^{\underline{a}} \\
\text { intervención }\end{array}$ & $\begin{array}{c}\text { Inyección } \\
\text { Macroplastique } \mathbb{} \\
\text { Buen resultado }\end{array}$ \\
\hline 7 & $8 a$ & $\begin{array}{l}\text { Persistencia } \\
\text { RVU Bilateral }\end{array}$ & $\begin{array}{c}2^{\mathrm{q}} \text { inyección } \\
\text { Macroplastique } \mathbb{R} \\
\text { bilateral }\end{array}$ & Bueno bilateral & $\begin{array}{c}\text { Reaparece RVU } \\
\text { bilateral } \\
53 \mathrm{~m} \text { post-2 } \\
\text { intervención }^{\mathrm{a}}\end{array}$ & Cistoplastia \\
\hline 8 & $7 a+7 m$ & \begin{tabular}{c|}
$\mathrm{RVU}$ \\
contralateral
\end{tabular} & $\begin{array}{c}\text { Inyección } \\
\text { Macroplastique } \mathbb{}\end{array}$ & Bueno & $\begin{array}{l}\text { PNA + ectasia } \\
\text { bilateral } \\
42 \text { m post- } 2^{a} \\
\text { intervención }\end{array}$ & Cistoplastia \\
\hline
\end{tabular}


incrementando el riesgo de: dilatación ureteral, pielonefritis, "nefropatía por reflujo", y disminución de la función del riñón afecto.

El tratamiento de la VN mediante cateterismo limpio intermitente asociado a la administración oral de anticolinérgicos, es la medida esencial para minimizar la aparición de las complicaciones mencionadas, al facilitar un vaciado suficiente y disminuir la hiperpresión. El empleo de inyecciones intravesicales de toxina botulínica, aún conociendo sus efectos temporales, contribuye a conseguir este objetivo.

El RVU se detecta en el 27 al $47 \%$ de pacientes con VN $(5,7-10)$, y en algunos casos ya está presente cuando valoramos a los recién nacidos con mielodisplasia $(4,11,12)$. Su tratamiento, en general, sigue un esquema similar al aplicado para la resolución de los RVU primarios. Aquellos de bajo grado son tratados de manera conservadora, opción que contempla el empleo del $\mathrm{Cl}$ y la administración de anticolinérgicos, a las medidas habituales que pautamos en los esenciales. Los de alto grado, agotada la pauta conservadora, quizás requieran de algún procedimiento quirúrgico para solucionar el paso retrógrado de orina al uréter: reimplantación ureteral, inyección subureteral de biomateriales, e incluso su solución se contemple dentro del tratamiento integral de la severa disfunción vesical neurógena y propongamos una cistoplastia de aumento o una derivación urinaria cutánea según la edad del paciente. Los RVU de bajo grado tratados correctamente, si permiten la aparición de pielonefritis de repetición, o se comprueba una disminución de la función renal, atribuible a los efectos del propio reflujo o a la asociación de bacteriuria-reflujo-obstrucción funcional, precisan de tratamiento quirúrgico como ocurre en el manejo del RVU esencial o primario.

La ureterocistoneostomía antirreflujo practicada mediante cirugía "a cielo abierto", ha demostrado su eficacia en el tratamiento quirúrgico de los RVU secundarios a disfunciones vesicales neurógenas. En 1988 publicamos nuestra casuística de reimplantaciones ureterales según técnica de Cohen (13) y de los 46 uréteres reimplantados logramos la desaparición del RVU en 41 (89.13\%), aunque observamos cuatro estenosis ureterales y una persistencia del RVU. Entonces, actuábamos sistemáticamente de manera bilateral, no pudiendo obviamente constatar RVU contralateral en el postoperatorio y reimplantando uréteres que no presentaban RVU (10 de 46 en aquella revisión). Nuestros resultados estaban en la línea de los publicados por otros autores (14-16).

La introducción del TE mediante la inyección subureteral de diferentes biomateriales, ha pasado a ser el procedimiento de elección en el manejo quirúrgico del RVU primario e incluso de los secundarios. Menos tiempo operatorio, postoperatorio con mínimas molestias, pocas complicaciones, estancia hospitalaria corta y procedimiento más fácil de realizar, sobre todo en las vejigas trabeculadas, son las ventajas del método. Los resultados obtenidos en los secundarios a vejiga neurógena son ligeramente inferiores a los alcanzados con los primarios, pero suficientes para proponer su empleo de manera prioritaria $(14,16-19)$.
Nuestra conducta en los RVU unilaterales ha sido intervenir sólo sobre el uréter refluyente; de esta manera en 2 de los cinco casos hemos comprobado RVU contralateral en el control postoperatorio, y en un tercero fue constatado a los 19 meses de la intervención. La etiología del RVU contralateral responde al incremento de presiones que ha de soportar la unión urétero-vesical no intervenida, al cerrarse la válvula de escape que supone el uréter refluyente. Debemos precisar que el uréter exento de RVU, ha sido inspeccionado durante la cistoscopia no presentando anormalidad alguna en su ubicación, morfología y la longitud del trayecto submucoso. Nuestra táctica a la vista de estos resultados debería cambiar tratando ambos meatos en el mismo acto quirúrgico, siguiendo la misma conducta que en los casos intervenidos mediante cirugía "abierta" ya comentados.

El empleo de la inyección intravesical de toxina botulínica en el tratamiento de la VN en los pacientes en edad pediátrica, con alteraciones urodinámicas de hiperreflexia, capacidad vesical disminuida e incluso de acomodación deficiente ha logrado mejorar las malas condiciones dinámicas vesicales, aunque sus efectos son temporales. $\mathrm{Si}$ los casos con RVU de alto grado y disfunción vesical severa, los tratamos con la inyección simultánea de toxina botulínica intravesical y de sustancia inerte subureteral, es posible que logremos mejores resultados en la curación del $\mathrm{RVU}$, aunque habrá que verificar su desaparición cuando disminuyan los efectos de la toxina sobre el detrusor.

La curación del RVU en la VN no soluciona la problemática del tratamiento de la disfunción vesical. La vejiga neurógena ha de ser tratada de manera integral, evitando, en la medida de lo posible, la presencia de hiperpresión vesical derivada de la alteración de la capacidad, acomodación y de la falta de sinergismo entre vejiga y uretra. El cateterismo vesical intermitente y la administración de fármacos anticolinérgicos logran mejorar el comportamiento urodinámico y han solucionado e impedido la morbilidad del RVU de bajo grado en un alto porcentaje de casos (15). $\mathrm{Si}$ indicamos el tratamiento quirúrgico del RVU, la inyección subureteral de biomateriales como Macroplastique $\AA$ - Deflux $\AA^{\circledR}$ es una opción válida por los buenos resultados alcanzados y la escasez de complicaciones, pero es necesario recalcar que todos los pacientes con VN necesitan de controles clínicos y por lo menos ecográficos, para seguir su evolución. Aquellos pacientes con vejigas de comportamiento urodinámico de riesgo, donde las fibras musculares del detrusor han sido sustituidas por tejido fibroso, es posible que requieran de otros procedimientos quirúrgicos como la cistoplastia de aumento con la finalidad de mejorar sus condiciones urodinámicas, que el RVU curado anteriormente no reaparezca y evitar el deterioro funcional renal, a pesar de su correcto tratamiento con opciones menos "agresivas".

\section{CONCLUSIONES}

El tratamiento endoscópico del RVU en los pacientes con VN es una opción de probada eficacia. En nuestra casuística hemos obtenido un $72.7 \%$ de buenos resultados después de la primera inyección. 
La persistencia del RVU o la presencia de reflujo contralateral han sido las complicaciones observadas.

Todo paciente con VN ha de ser controlado durante la edad pediátrica ante el riesgo de aparición del RVU ya curado, sobre todo en las vejigas con acomodación y capacidad alteradas y con presión de escape alta.

\author{
Abreviaturas \\ TE: Tratamiento endoscópico. \\ RVU: Reflujo vesicoureteral \\ $V N$ : Vejiga neurógena \\ $\mathrm{Cl}$ : Cateterismo intermitente \\ CUMS: Cistouretrografía miccional seriada.
}

\section{BIBLIOGRAFÍA Y LECTURAS RECOMENDADAS ("lectura de interés $\mathrm{y}^{* *}$ lectura fundamental)}

1. PALMER, L.S.; RICHARDS, I.; KAPLAN, W.E.: "Age related bladder capacity and bladder capacity growth in children with myelomeningocele". J. Urol., 158: 1261, 1997.

2. INTERNATIONAL REFLUX STUDY COMMITTEE.: "Medical versus surgical treatment of primary vesicoureteral reflux: A prospective international reflux study in children". J. Urol., 125: 277, 1981.

3. PURI, P.: "Ten year experience with subureteric Teflon (polytetrafluoroethylene) inyection (STING) in the treatment of vesico-ureteric reflux". Br. J. Urol., 75: 126, 1995.

4. BAUER, S.B.: "Early evaluation and management of children with spina bifida". Urologic surgery in neonates \& young infants. 252-264. Ed. Saunders Company. Philadelphia, 1988.

5. ROMERO MAROTO, J.; LÓPEZ, C.; GÓMEZ, J.J.: "Mielodisplasia". Urodinámica Clínica. 2a Edición. Cap 25, 425-437. Jarpyo Editores. Madrid, 1995.

6. SIDI, A.A.; DYSKSTRA, D.D.; GONZALEZ, R.: "The value of urodynamic testing in the management of neonates with myelodysplasia: A prospective study". J. Urol., 135: 90, 1986.

7. COHEN, R.A.; GIL RUSHTON, H.; BARRY BELMAN, A. y cols.: "Renal scarring and vesicoureteral reflux in children with myelodysplasia". J. Urol., 144: 541,1990
8. LÓPEZ PEREIRA, P.; EIRE, P.; MARTÍNEZ URRUTIA, M.J. y cols.: "Diagnóstico urodinámico y tratamiento en la disfunción vesical neurógena". Cir. Ped., 5: $171,1992$.

9. FLOOD, H.D.; RITCHNEY, M.L.; BLOOM, D.A. y cols.: "Outcome of reflux in children with myelodysplasia managed by bladder pressure monitoring". J. Urol., 152: 1574, 1994.

10. AGARWAL, S.K.; Mc LOIRE, G.A.; GREWAL, D. y cols.: "Urodynamics correlates of resolution of reflux in meningomyelocele patientes". J. Urol., 158: 580, 1997.

11. BARRIOS FONTOBA, J.E.; ESTORNELL MORAGUES, F.; MERENCIANO CORTINA, F. y cols.: "Valoración neonatal del aparato urinario en el paciente mielodisplásico". Urod. A., 7: 209, 1994.

12. GAUM, L.D.; WESE, F.X.; ALTON, D.J. y cols.: "Radiologic investigation of the urinary tract in the neonate with myelomeningocele". J. Urol., 127: 510, 1982.

13. ESTORNELL MORAGUES, F.; GUTIÉRREZ SANROMÁN, C.; VILA CARBÓ, J.J. y cols.: "Ureterocistoneostomía antirreflujo según técnica de Cohen. A propósito de 581 reimplantaciones". Actas Urol. Esp., 12: $111,1988$.

*14. GRANATA, C.; BUFFA, P.; DI ROVASENDA, E. y cols.: "Treatment of vesico-ureteric reflux in children with neuropathic bladder: A comparison of surgical and endoscopic correction". J. Pediatr. Surg., 34: 1836, 1999.

15. MORIOKA, A.; MIYANO, T.; ANDO, K. y cols.: "Management of vesicoureteral reflux secondary to neurogenic bladder". Pediatr. Surg. Int., 13: 584, 1998.

*16. ENGEL, J.D.; PALMER, L.S.; CHENG, E.Y. y cols.: "Medical versus endoscopic correction of vesicoureteral reflux in children with neurogenic bladder dysfunction". J. Urol., 157: 2291, 1997.

17. SERRANO DURBÁ, A.; GÓMEZ PÉREZ, L.; ESTORNELL MORAGUES, J.F. y cols.: "Eficacia a largo plazo del tratamiento endoscópico en el reflujo vesicoureteral de etiología secundaria con polidimetilsiloxano". Actas Urol. Esp., 30: 692, 2006.

18. PEREZ-BRAYFIELD, M.; KIRSCH, A.J.; HENSLE, T.W. y cols.: "Endoscopic treatment with dextranomer/hyaluronic acid for complex cases of vesicoureteral reflux". J. Urol., 172: 1614, 2004.

19. MISRA, D.; POTTS, S.R.; BROWN, S. y cols.: "Endoscopic treatment of vesico-ureteric reflux in neurogenic bladder. 8 years experience". J. Pediatr. Surg., 31: 1262, 1996. 